\title{
Whole-body vibration training versus conventional balance training in patients with severe COPD_a randomized, controlled trial
}

\author{
Rainer Gloeckl 1,2* ${ }^{*}$, Tessa Schneeberger ${ }^{1,2}$, Daniela Leitl ${ }^{1,2}$, Tobias Reinold ${ }^{3}$, Christoph Nell ${ }^{4}$, Inga Jarosch ${ }^{1,2}$,
} Klaus Kenn ${ }^{1,2}$ and Andreas R. Koczulla $a^{1,2,5}$

\begin{abstract}
Background: Whole-body vibration training (WBV) performed on a vibration platform can significantly improve physical performance in patients with chronic obstructive pulmonary disease. It has been suggested that an important mechanism of this improvement is based on an improvement in balance. Therefore, the aim of this study was to investigate the effects of WBV compared to conventional balance training.
\end{abstract}

Methods: 48 patients with severe COPD ( $\mathrm{FEV}_{1}: 37 \pm 7 \%$ predicted) and low exercise performance ( 6 min walk distance (6MWD): $55 \pm 10 \%$ predicted) were included in this randomized controlled trial during a 3 week inpatient pulmonary rehabilitation. All patients completed a standardized endurance and strength training program. Additionally, patients performed 4 different balance exercises 3x/week for 2 sets of 1 min each, either on a vibration platform (Galileo) at varying frequencies (5-26 Hz) (WBV) or on a conventional balance board (BAL). The primary outcome parameter was the change in balance performance during a semi tandem stance with closed eyes assessed on a force measurement platform. Muscular power during a countermovement jump, the $6 \mathrm{MWD}$, and $4 \mathrm{~m}$ gait speed test (4MGST) were secondary outcomes. Non-parametric tests were used for statistical analyses.

Results: Static balance performance improved significantly more $(p=0.032)$ in favor of WBV (path length during semi-tandem stand: $-168 \pm 231 \mathrm{~mm}$ vs. $+1 \pm 234 \mathrm{~mm}$ ). Muscular power also increased significantly more $(p=0.001)$ in the WBV group $(+2.3 \pm 2.5 \mathrm{~W} / \mathrm{kg}$ vs. $-0.1 \pm 2.0 \mathrm{~W} / \mathrm{kg})$. $6 \mathrm{MWD}$ improved to a similar extent in both groups (WBV: $48 \pm 46 \mathrm{~m}, p<0.001 \mathrm{vs}$. BAL: $38 \pm 32 \mathrm{~m} ; p<0.001)$ whereas the 4MGST increased significantly only in the WBV-group $\left(0.08 \pm 0.14 \mathrm{~m} / \mathrm{s}^{2}, p=0.018\right.$ vs. $\left.0.01 \pm 0.11 \mathrm{~m} / \mathrm{s}^{2}, p=0.71\right)$.

Conclusions: WBV can improve balance performance and muscular power significantly more compared to conventional balance training.

Trial registration: Clinical-Trials registration number: NCT03157986; date of registration: May 17, 2017. https://clinicaltr ials.gov/ct2/results?cond=\&term =NCT03157986\&cntry=\&state=\&city=\&dist $=$

\footnotetext{
*Correspondence: rainer.gloeckl@gmx.de

${ }^{1}$ Department of Pulmonary Rehabilitation, Philipps-University

of Marburg, German Center for Lung Research, Malterhoeh 1, 83471

Schoenau Am Koenigssee, Marburg, Germany

Full list of author information is available at the end of the article
}

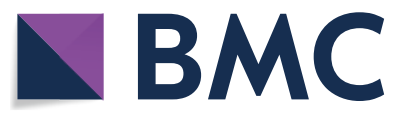

(c) The Author(s) 2021. Open Access This article is licensed under a Creative Commons Attribution 4.0 International License, which permits use, sharing, adaptation, distribution and reproduction in any medium or format, as long as you give appropriate credit to the original author(s) and the source, provide a link to the Creative Commons licence, and indicate if changes were made. The images or other third party material in this article are included in the article's Creative Commons licence, unless indicated otherwise in a credit line to the material. If material is not included in the article's Creative Commons licence and your intended use is not permitted by statutory regulation or exceeds the permitted use, you will need to obtain permission directly from the copyright holder. To view a copy of this licence, visit http://creativecommons.org/licenses/by/4.0/. The Creative Commons Public Domain Dedication waiver (http://creativeco mmons.org/publicdomain/zero/1.0/) applies to the data made available in this article, unless otherwise stated in a credit line to the data. 
Keywords: Chronic obstructive pulmonary disease, Pulmonary rehabilitation, Exercise, Neuromuscular power, Force measurement platform, Vibration platform

\section{Introduction}

Whole-body vibration training (WBV) is a training modality where a subject stands on a vibration platform that induces sinusoidal oscillations to the body which evolve reflex-induced muscle contractions [1]. It has been shown that neuromuscular activity during WBV is increased compared to similar exercises without vibration $[2,3]$. Therefore, within the past two decades, there has been increasing interest in the use of WBV as a training intervention in several therapeutically areas like chronic low back pain [4], osteoporosis [5], neurological disorders [6], or geriatric rehabilitation [7]. There is also increasing evidence that WBV is a beneficial exercise modality in patients with chronic obstructive pulmonary disease [8]. In a recent study from our workgroup, we found that improvements in exercise performance following a WBV training program were related to improvements in balance performance and muscular power output [9]. Furthermore, these neuromuscular adaptations seemed to be an important mechanism of improving exercise performance especially in COPD patients with impaired balance performance and low exercise performance [9]. Currently, there is a large body of evidence showing that postural control and balance performance are impaired in COPD compared to healthy age-matched controls $[10,11]$. This leads to an increased risk for falls in COPD [12]. A large cohort study analyzing more than 200.000 subjects has shown that COPD patients are $55 \%$ more likely to have fall incidents compared to nonCOPD subjects [13]. Since falls are associated with an increased risk of injuries, injury-related disability, and even an increased risk of all-cause mortality, improving balance performance and preventing falls has become an important treatment target in COPD [14]. Thus, measures of balance performance are also recommended by the current ATS/ERS pulmonary rehabilitation guidelines to be included in the clinical assessment of patients with COPD [15].

Hence, the aim of our study was to investigate the effects of a balance training using WBV vs. a conventional balance training on balance performance and muscular power in COPD patients with an impaired physical status.

\section{Methods}

\section{Study design}

Patients admitted to an inpatient rehabilitation program at the Schoen Klinik Berchtesgadener Land (Schoenau am Koenigssee, Germany) were screened for eligibility to participate in this randomized controlled trial. Patients were recruited between May 2017 and August 2019. This study was submitted to the Clinical Trials Registry (www. clinicaltrials.gov, NCT03157986) and approved by the Ethics Committee of the Philipps-University of Marburg (approval number: 27/17).

\section{Study population}

Inclusion criteria were: age between 50 and 80 years, confirmed diagnosis of COPD stage III or IV according to the Global Initiative for Chronic Obstructive Lung Disease (GOLD) [16] guidelines, a 6 min walk distance $(6 \mathrm{MWD})<70 \%$ predicted, and providing a written informed consent [17]. Patients with a current acute COPD exacerbation, a carbon dioxide pressure $\geq 45 \mathrm{mmHg}$ at rest, or any contraindications for WBV (e.g. an artificial joint in the lower extremities) were excluded.

\section{Intervention}

Patients participated in a 3 week comprehensive multimodal and multidisciplinary inpatient pulmonary rehabilitation (PR). The PR program was provided on 6 days per week consisting of medical care, endurance training, strength training, respiratory physiotherapy, education, nutritional and psychological counseling. For detailed information on the standardized endurance and strength training program see Additional file 1: Tables S1).

For this study, all patients performed a supplemental supervised balance training on 3 non-consecutive days per week (Mon/Wed/Fri). Patients were randomized and allocated to either a WBV group or a conventional balance training group (BAL). The WBV group performed a balance training on a side-alternating vibration platform (Galileo, Novotec, Medical GmbH, Pforzheim Germany) at varying frequencies $(5-26 \mathrm{~Hz})$ and $4-5 \mathrm{~mm}$ peak-topeak displacement (see Table 1 and Additional file 1: Table S2 for a detailed description of WBV settings). The varying frequencies were used to provide different stimuli to the patients' motor control. Patients in the BAL group performed the same exercises on a conventional balance board.

Balance training sessions were similar between groups except for the surface and consisted of four exercises as described in Table 1 \& Fig. 1. Each balance training session took about 20 min (including short breaks of 1-min duration between each exercise). Patients were instructed 
Table 1 Balance exercises and vibration plate settings

\begin{tabular}{|c|c|c|c|c|}
\hline & Exercises ( $2 \times 1 \mathrm{~min}$ each) & WBV group frequencies & $\begin{array}{l}\text { Conventional balance } \\
\text { training }\end{array}$ & Variations \\
\hline 1 & Dynamic squat exercise & $\begin{array}{l}\text { Mon: } 26 \mathrm{~Hz} \\
\text { Wed: } 18 \mathrm{~Hz} \\
\text { Fri: } 22 \mathrm{~Hz}\end{array}$ & Balance board & Slight finger contact on a handlebar \\
\hline 2 & Dynamic heel raises & $\begin{array}{l}\text { Mon: } 22 \mathrm{~Hz} \\
\text { Wed: } 26 \mathrm{~Hz} \\
\text { Fri: } 18 \mathrm{~Hz}\end{array}$ & Balance board & Free standing \\
\hline 3 & Static one-leg stance & $\begin{array}{l}\text { Mon: } 15 \mathrm{~Hz} \\
\text { Wed: } 10 \mathrm{~Hz} \\
\text { Fri: } 5 \mathrm{~Hz}\end{array}$ & Balance board & Additional arm/leg movements \\
\hline 4 & Dynamic lunge step & $\begin{array}{l}\text { Mon: } 18 \mathrm{~Hz} \\
\text { Wed: } 22 \mathrm{~Hz} \\
\text { Fri: } 26 \mathrm{~Hz}\end{array}$ & Balance board & Throwing balls \\
\hline
\end{tabular}

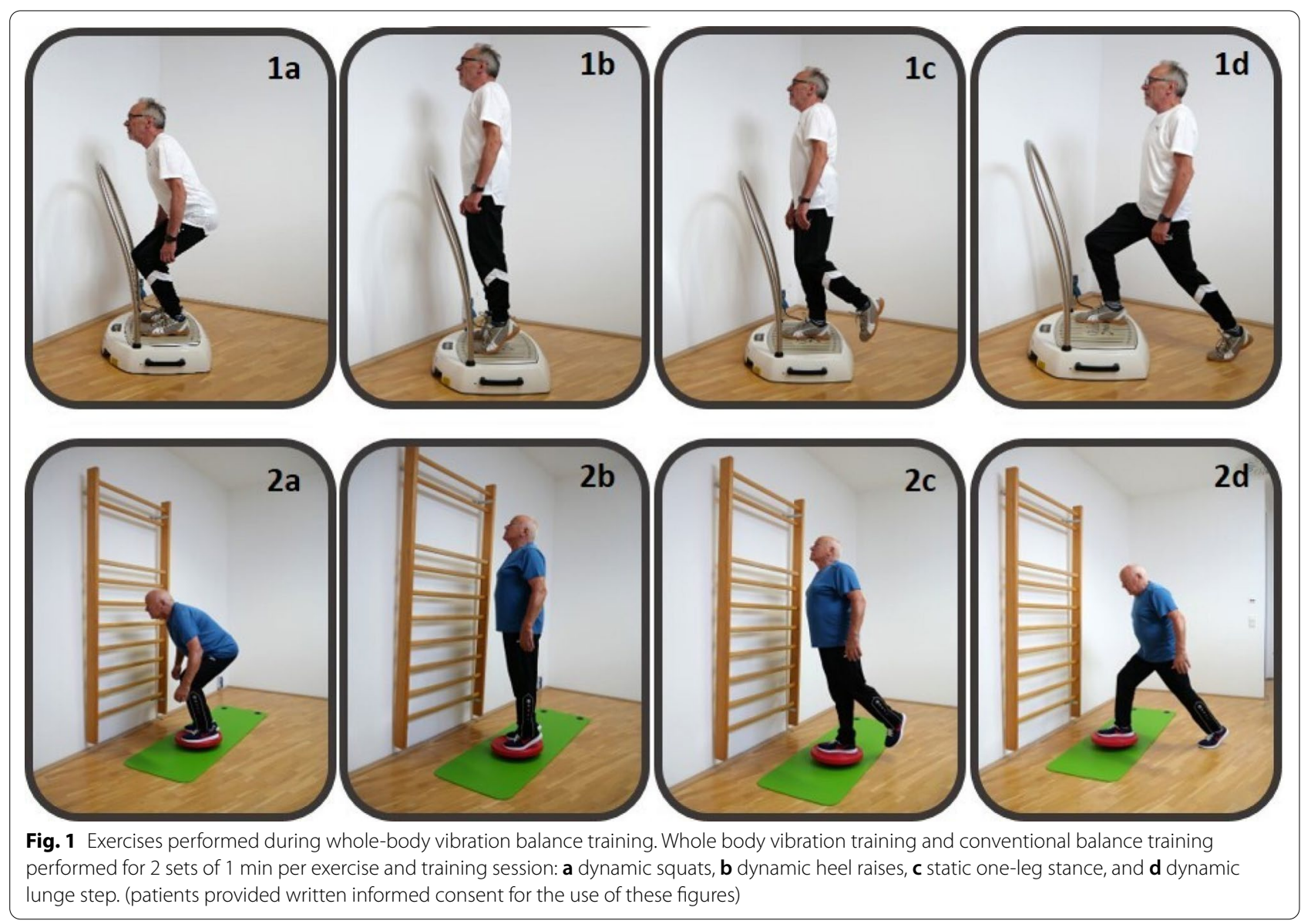

to perform exercises with slow-motion movements $(3 \mathrm{~s}$ concentric and eccentric). When a participant was able to perform an exercise with only little instability, the difficulty was progressively increased by adding more challenging conditions (e.g. from slight finger contact on a handlebar and freestanding to closed eyes and additional arm movements to irritate balance ability). The aim was to reach an individual level of difficulty that forced patients for continuous counter-movements. In the WBV group exercise intensity varied also by using different vibration frequencies between 5 to $26 \mathrm{~Hz}$ during each session (see Table 1). All balance training sessions in both 
groups were individually supervised by an experienced therapist that corrected and adapted exercise difficulty to the patients individual performance.

\section{Outcomes and measures Primary outcome-balance performance}

The primary outcome parameter of the study was the change in balance performance during semi tandem stance (Fig. 2) with closed eyes. Further standing positions to test the postural balance were Romberg stance (eyes closed) and one-leg stance (eyes open). For all 3 balance tests patients were instructed to stand as still as possible for $10 \mathrm{~s}$. The best out of three attempts was used for analysis. The balance tests were assessed using a ground reaction force platform (Leonardo Mechanograph, Novotec Medical, Pforzheim, Germany) with 8 integrated force sensors $(800 \mathrm{~Hz}$ each) to calculate the center of force [18]. The outcome "absolute path length" in mm represents a better stability with lower values.

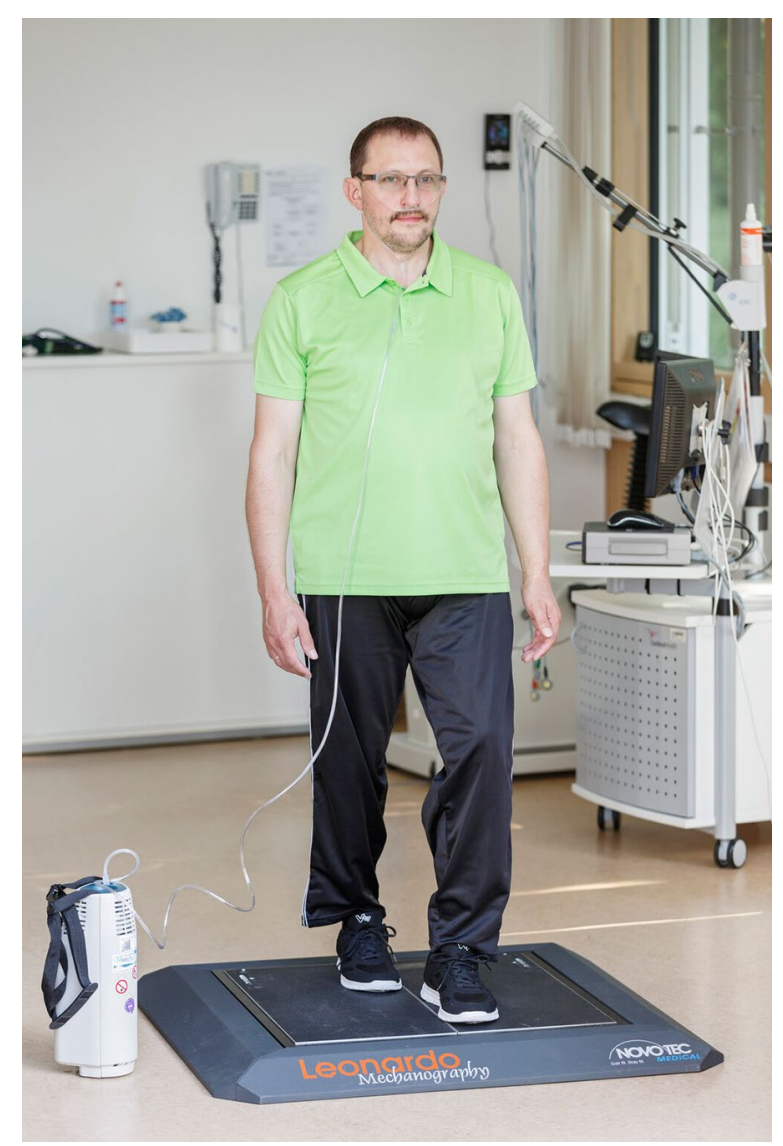

Fig. 2 COPD Patient performing a semi-tandem stance balance test on a force measurement platform. Patient provided written informed consent for the use of this picture

\section{Secondary outcomes}

Neuromuscular performance To measure muscular power a countermovement jump was performed on the Leonardo platform [19]. Patients were asked to jump as high as possible with using arm-swing [20]. The best test out of three jumps was used for analysis. Peak Watt per kg body weight was used as outcome.

6-min walk distance The 6-min walk test (6-MWT) was performed following the ATS/ERS guidelines [21] with the best out of two tests being used for analysis. The minimal important difference in COPD is estimated to be $30 \mathrm{~m}[21]$.

4-m gait speed test A 4-m gait speed test has been performed according to Kon et al. [22]. The minimal important difference in COPD is estimated at $0.11 \mathrm{~m} / \mathrm{s}$ [23].

Muscular strength A dynamometer (MicroFET2, Hoggan, Scientific LLC, UT) was fixed in a leg curl device to measure peak isometric knee extension strength at $90^{\circ}$ knee angle.

Sit to stand tests (STST) A five-repetition STST (outcome: test duration in seconds) [24] and a 1 min STST (outcome: number of repetitions) [25] were performed from a $46 \mathrm{~cm}$ height bench with arms crossed in front of the chest.

\section{Sample size calculation}

The a priori sample size computation based on the results of a former trial [9] and included the following assumptions: changes in the APL of the semi-tandem stance with closed eyes (= primary outcome) of $-272 \pm 369 \mathrm{~mm}$ (WBV) and 76 $\pm 277 \mathrm{~mm}$ (control), power 95\%, alpha of $5 \%$ and two-sided, independent $\mathrm{t}$-test. Based on these assumptions, a sample size of 24 per group was necessary to achieve this power at this effect size.

\section{Randomization and allocation concealment}

Stratification for randomization was done according to balance performance using a threshold of $750 \mathrm{~mm}$ absolute path length during the baseline semi-tandem stance. The investigator responsible for patient recruitment received group allocation by a third party picking a sealed envelope which contained group allocation.

\section{Blinding}

Blinding of the study participants was not possible within the study setting due to the nature of the intervention. However, the outcome assessors and the statistician were blinded to the group allocation. 


\section{Statistical methods}

Results were provided by mean values \pm SD or $95 \%$ CI. For comparing pre to post PR effects, a two-tailed Wilcoxon rank-sum test was applied. The Mann-Whitney U-test was used to compare the between-group differences. The significance level was set at $p<0.05$. Regression models with a forward variable selection algorithm were used to test for significant predictors of change following the intervention. Statistical analyses were performed using SPSS 23 (IBM, USA).

\section{Results}

Fifty-seven out of 110 eligible patients met the inclusion criteria and were randomized to the trial. Nine patients dropped out of the study (for reasons see flow chart in Fig. 3) and 48 patients completed all assessments. Patients had severe airflow obstruction (FEV1: $37 \pm 7 \%$ predicted) and impaired exercise capacity (6-MWD: $354 \pm 70 \mathrm{~m}, 55 \pm 10 \%$ predicted). For more baseline measures see Table 2. Patients performed on average $8 \pm 1$ out of a maximum of nine possible balance training sessions in the WBV group and $7 \pm 1$ sessions in the control group. The primary outcome (change in APL during semi-tandem stance) improved significantly more in favor of the WBV group (between-group difference: $167 \mathrm{~mm}, \mathrm{p}=0.032$ ) with a medium effect size (cohen's d 0.72; Fig. 4). Patients in the control group did not significantly improve in any balance test. Another measure of neuromuscular performance, the countermovement jump also improved significantly more in favor of the WBV group $(+2.3 \mathrm{~W} / \mathrm{kg}$ vs. $-0.1 \mathrm{~W} / \mathrm{kg}, p=0.001$; Table 3). The $4 \mathrm{~m}$ gait speed test improved significantly only in the WBV group $\left(0.08 \mathrm{~m} / \mathrm{s}^{2}, p=0.018\right.$ vs. $0.01 \mathrm{~m} /$ $\left.\mathrm{s}^{2}, p=0.715\right)$. However, walking performance during the 6-MWT increased similarly in both groups (see Additional file 1: Figures S1-S4). It was not possible to set up a regression model, since no stable model could not be achieved, which might be related to the small number of patients.

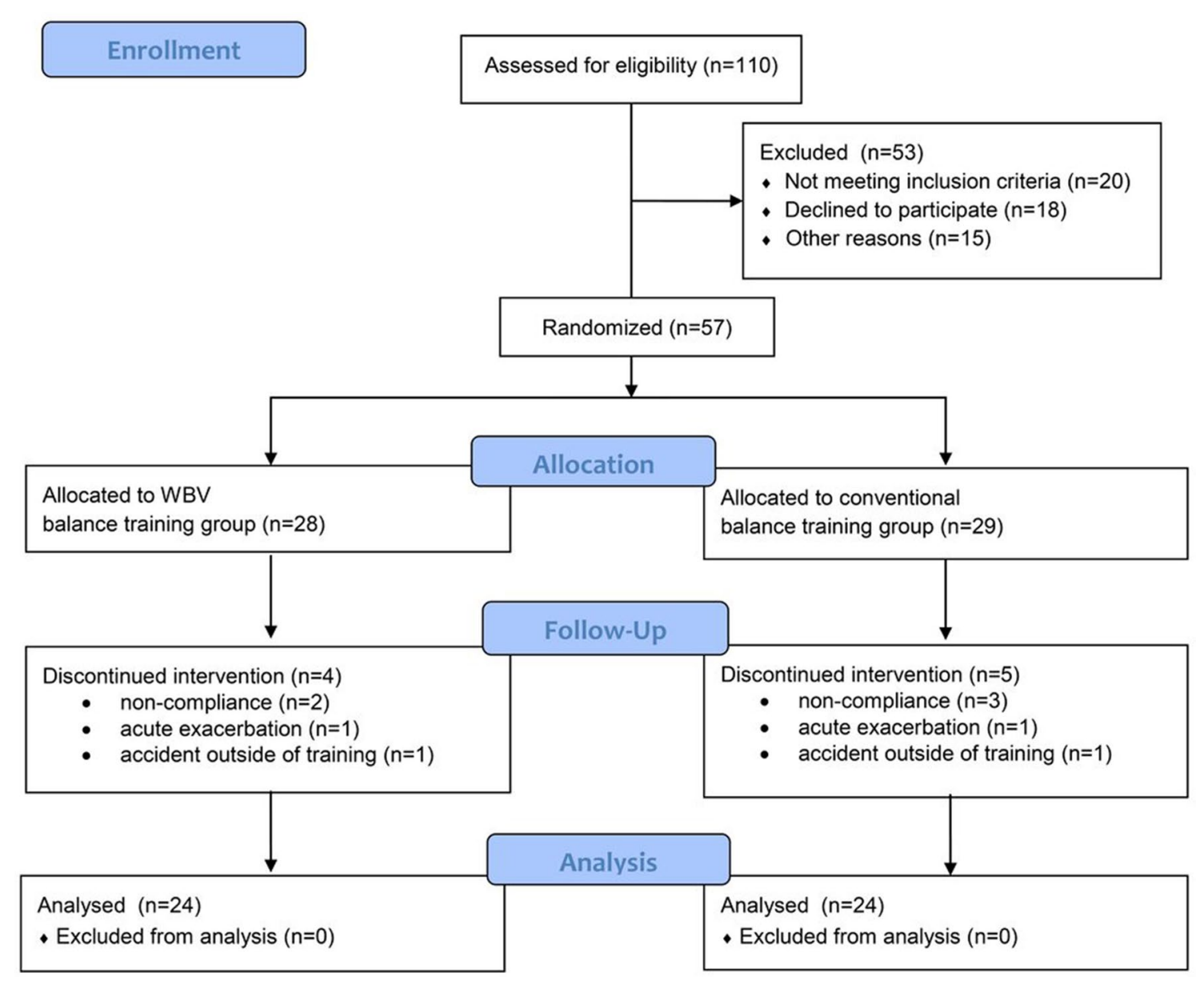

Fig. 3 Consort flow diagram 
Table 2 Baseline characteristics

\begin{tabular}{|c|c|c|c|}
\hline & WBV balance training group & conventional balance training group & $p$-values \\
\hline \multicolumn{4}{|l|}{ General } \\
\hline $\mathrm{n}$ & 24 & 24 & - \\
\hline Age, ys & $65 \pm 7$ & $66 \pm 8$ & 0.415 \\
\hline $\mathrm{BMI}, \mathrm{kg} / \mathrm{m}^{2}$ & $25.3 \pm 5.1$ & $26.0 \pm 5.2$ & 0.398 \\
\hline LTOT, n [\%] & $11(46 \%)$ & $8(33 \%)$ & 0.376 \\
\hline $\mathrm{FEV}_{1}, \%$ predicted $^{\#}$ & $36.2 \pm 8.4$ & $38.0 \pm 6.3$ & 0.466 \\
\hline RV, \%predicted ${ }^{\#}$ & $218.6 \pm 40.4$ & $233.4 \pm 37.1$ & 0.301 \\
\hline $\mathrm{pO}_{2}$ at rest and ambient air, $\mathrm{mmHg}$ & $61.5 \pm 5.5$ & $63.8 \pm 4.1$ & 0.155 \\
\hline Comorbidities, $\mathrm{n}$ & $2.5[0-5]$ & $2.4[0-6]$ & 0.756 \\
\hline Falls during the previous year, n (\%) & $2(8 \%)$ & $5(21 \%)$ & 0.389 \\
\hline \multicolumn{4}{|l|}{ Static balance tests } \\
\hline Romberg stance/eyes closed, APL [mm] & $352 \pm 197$ & $387 \pm 225$ & 0.578 \\
\hline Semi tandem stance/eyes closed, APL [mm] & $800 \pm 268$ & $887 \pm 417$ & 0.750 \\
\hline One-leg stance/eyes open, APL [mm] & $786 \pm 356$ & $731 \pm 276$ & 0.844 \\
\hline \multicolumn{4}{|l|}{ Exercise performance tests } \\
\hline $6 \mathrm{MWD}, \mathrm{m}$ & $349 \pm 68$ & $360 \pm 73$ & 0.621 \\
\hline 6MWD, \%predicted & $53 \pm 10$ & $57 \pm 10$ & 0.155 \\
\hline Knee extension, peak force [N] & $267 \pm 74$ & $282 \pm 99$ & 0.733 \\
\hline Knee extension, peak force [\%predicted] & $79 \pm 17$ & $87 \pm 19$ & 0.249 \\
\hline Countermovement jump [W/kg] & $23.9 \pm 5.1$ & $23.3 \pm 6.0$ & 0.517 \\
\hline 5-repetition sit-to-stand test [sec.] & $13.4 \pm 3.9$ & $12.3 \pm 4.8$ & 0.091 \\
\hline 1 min sit-to-stand test [rep] & $18.3 \pm 4.9$ & $19.8 \pm 6.5$ & 0.109 \\
\hline 4 m gait speed test $\left[\mathrm{m} / \mathrm{s}^{2}\right]$ & $0.90 \pm 0.15$ & $0.97 \pm 0.15$ & 0.152 \\
\hline
\end{tabular}

Data are presented as mean \pm SD or [min/max]

6MWD 6-min walk distance, $A P L$ absolute path length, BMI Body-Mass-Index, FEV1 forced expiratory volume in $1 \mathrm{~s}$, LTOT long-term oxygen therapy, pO2 partial oxygen pressure, WBV whole-body vibration training

\# lung function was measured by bodyplethysmography (Master Screen Body, Jaeger, Germany) using reference equations from the Global Lung Function Initiative [26]

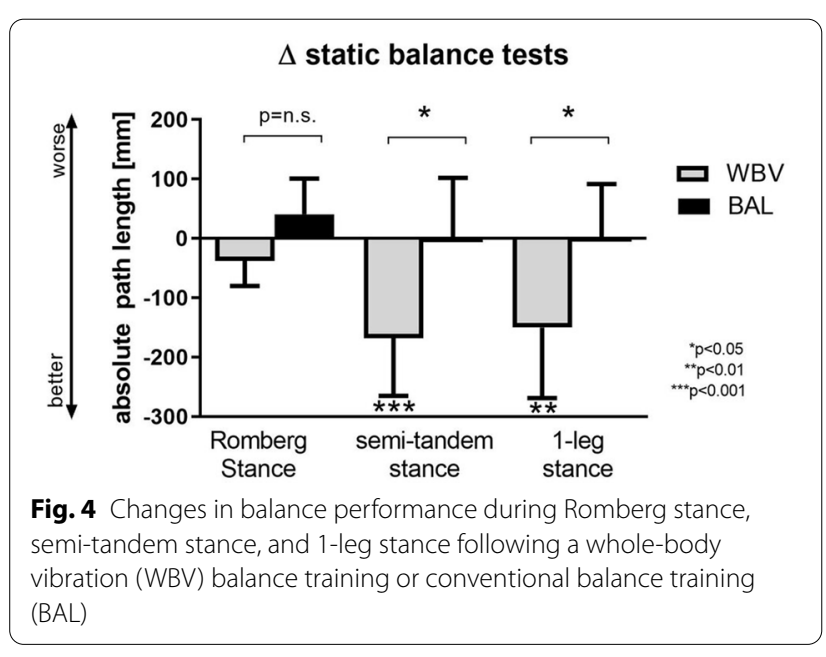

No adverse event related to the training protocol was observed.

\section{Discussion}

In our study, we found that WBV improved balance and neuromuscular performance significantly more compared to conventional balance training in COPD patients. It is known from former studies that in COPD patients postural control is impaired and gait parameters are altered compared to healthy age-matched controls $[10,11,27]$. Furthermore, COPD patients perceive an increased fear of falls than non-COPD individuals [27]. These impairments are of clinically relevance because they are associated with a lower functional performance and independence in activities of daily living [10]. COPD patients in our study had a $50 \%$ reduced balance performance compared to healthy elderly subjects [28]. This magnitude of balance impairment was similar to the one reported earlier in COPD [9]. A recent meta-analysis has identified several independent risk factors (like age, falls history, balance impairment, supplemental oxygen etc.) for falls in stable COPD [29]. However, impaired balance performance was the only risk factor that has the potential to improve. 
Table 3 Changes in outcome measures following 3 weeks of PR with whole body vibration (WBV) balance training or conventional balance training

\begin{tabular}{|c|c|c|c|c|c|c|c|}
\hline & WBV balance training $(n=24)$ & $p$ & $\begin{array}{l}\text { conventional } \\
\text { balance training } \\
(n=24)\end{array}$ & $p$ & Between group difference & $p$ & $\begin{array}{l}\text { Effect size } \\
\text { Cohen's d }\end{array}$ \\
\hline \multicolumn{8}{|l|}{ Balance tests } \\
\hline $\begin{array}{l}\text { Semi tandem stance/eyes } \\
\text { closed, APL }[\mathrm{mm}]\end{array}$ & $-168(-265-71)$ & $<0.001$ & $1(-100-102)$ & 0.627 & $167(32-305)$ & 0.032 & 0.72 \\
\hline $\begin{array}{l}\text { Romberg stance/eyes closed, } \\
\text { APL [mm] }\end{array}$ & $-38(-80-4)$ & 0.103 & $41(-19-101)$ & 0.241 & $78(7-150)$ & 0.073 & 0.02 \\
\hline $\begin{array}{l}\text { One-leg stance/eyes open, } \\
\text { APL [mm] }\end{array}$ & $-150(-269--31)$ & 0.005 & $2(-88-91)$ & 0.744 & $152(4-300)$ & 0.017 & 0.68 \\
\hline \multicolumn{8}{|l|}{ Exercise performance tests } \\
\hline 6MWD, m & $47.9(28.2-67.5)$ & $<0.001$ & $38.4(24.6-52.2)$ & $<0.001$ & $-9.5(-33.0-14.0)$ & 0.250 & 0.23 \\
\hline Knee extension, peak force [N] & $35.1(16.6-53.6)$ & 0.001 & $25.9(15.3-36.4)$ & $<0.001$ & $-9.2(-29.4-10.9)$ & 0.406 & 0.28 \\
\hline $\begin{array}{l}\text { Countermovement jump [W/ } \\
\mathrm{kg}]\end{array}$ & $2.3(1.1-3.4)$ & 0.001 & $-0.1(-0.9-0.8)$ & 0.879 & $-2.3(-3.7--1.0)$ & 0.001 & 1.02 \\
\hline $\begin{array}{l}\text { 5-repetition sit-to-stand test } \\
\text { [sec.] }\end{array}$ & $-2.5(-3.7--1.2)$ & 0.001 & $-1.6(-3.0--0.2)$ & 0.012 & $0.9(-0.9-2.8)$ & 0.072 & 0.30 \\
\hline 1 min sit-to-stand test [rep] & $3.6(2.3-4.9)$ & $<0.001$ & $2.7(1.2-4.3)$ & 0.004 & $-0.9(-2.9-1.1)$ & 0.740 & 0.26 \\
\hline $4 \mathrm{~m}$ gait speed test $\left[\mathrm{m} / \mathrm{s}^{2}\right]$ & $0.08(0.02-0.14)$ & 0.018 & $0.01(-0.04-0.06)$ & 0.715 & $-0.07(-0.15-0.01)$ & 0.107 & 0.56 \\
\hline
\end{tabular}

Values are presented as mean and $95 \% \mathrm{Cl}$

6MWD 6 minute walk distance, APL absolute path length, BMI Body-Mass-Index

Two recent systematic reviews concluded that general exercise training interventions during PR can improve balance performance in COPD [30, 31]. Furthermore, PR including a specific balance training program seemed to have the largest effect on balance [31]. A randomized, controlled trial by Beauchamp et al. [32] compared a conventional PR program (including general exercise training) with PR plus balance training ( $3 \mathrm{x} /$ week à $30 \mathrm{~min}$ for 6 weeks). The authors concluded that the addition of a specific balance training program significantly improved balance performance and self-reported physical function in patients with moderate to severe COPD. In contrast, patients in the conventional balance training group in our study did not improve balance performance (only patients in the WBV group did). This difference might be related to the different balance assessment methods (clinical balance tests like Berg Balance Scale vs. objective measures by a force measurement platform in the current study). Furthermore, the longer exercise duration (30 vs. 20 min per session) and intervention period (6 vs. 3 weeks) might have contributed to this difference. There is some evidence that greater benefits in balance performance can be achieved by higher doses of exercise [33]. Also, our conventional balance training program was strictly limited to the same four exercises on the balance board and was not extended to other exercises or further unstable surfaces. However, this was chosen to keep the exercise content in the two groups as standardized as possible. Furthermore, the combination of a conventional balance training program in addition to a general exercise training might have alleviated the balance outcomes since general exercise training itself has a very strong training effect [34]. However, interestingly balance training performed on a WBV platform was able to improve balance performance significantly even after such a short training period.

Former studies in older adults have already shown that WBV improves objectively measured balance performance [35] as well as self-perceived balance confidence [36]. Furthermore, a randomized, controlled trial by Stolzenberg et al. used a similar methodology like in the current study (strength training plus conventional balance training or WBV) in 55 postmenopausal women with low bone density [28]. It was concluded that combining strength training with WBV improved neuromuscular performance significantly more than strength training plus conventional balance training. Also, a recent systematic review and meta-analysis (10 studies including 557 subjects) summarized that WBV significantly improved functional mobility in elderly subjects [37]. It was hypothesized that these improvements could be useful for the tasks of daily living [37].

Currently, the underlying mechanisms for the WBV benefits on neuromuscular function are not fully understood yet $[38,39]$. One of the most established explanations is that muscle contractions during WBV are induced by passive stretch reflexes [40, 41]. The micromovements during $\mathrm{WBV}$ facilitate the excitability of the 
spinal reflex [42] compared to voluntary muscle control during conventional exercise training. Marin and colleagues have shown that the vastus lateralis electromyographical activity increased by $57 \%$ when subjects stood in a squatting position on a WBV platform compared to an isometric squatting position without WBV [43].

Beyond these significant benefits of WBV on neuromuscular performance, we did not find a significant difference in 6-MWD. This might be related to the reason, that the 6-MWT is not a highly sensitive test to detect changes especially between two active training interventions that are very similar [34, 44]. Interestingly, the 4-m gait speed test improved significantly only in the WBV group. This test is more suitable to reflect a patient's usual walking speed. Furthermore, the 4-m gait speed test is known as a surrogate marker of physical frailty [45]. Peak quadriceps force improved similarly in both groups what is in line with findings from former studies $[9,46]$. Since WBV is not inducing a heavy muscular load during exercise a difference in muscular force was not expected.

Our study has some limitations that need to be discussed. First, we only included COPD patients with impaired exercise performance $(6 \mathrm{MWD}<70 \%$ predicted) what might limit the generalizability of our findings. However, we have chosen to do so because it is known that WBV has no additional effect on neuromuscular performance in well-trained athletes [47] and has only little effect in COPD patients with preserved exercise performance [9]. Therefore, WBV seems especially beneficial in subjects with impaired exercise and balance performance. The long-term maintenance of WBV training and its benefits in COPD e.g. on the risk of falls were not investigated and remain unknown. However, there is evidence that regular WBV over 8 to 12 months significantly reduced the risk of falls by $33 \%$ in subjects older than 50 years $[48,49]$

A strength of our study is that balance and neuromuscular performance were objectively measured by a wellvalidated force measurement platform and standardized test procedures.

\section{Conclusions}

To summarize, studies on the effects of exercise interventions on balance in COPD are still scarce, and more highquality research is required [30]. In our study, we found that balance training performed on a WBV platform is superior to improve objectively measured balance performance and muscular power compared to conventional balance board training in patients with severe COPD and functional impairments.
Abbreviations

6MWD: 6 Min walk distance; 6MWT: 6 Min walk test; APL: Absolute path length; ATS: American Thoracic Society; BAL: Balance training group; BMI: Body-Mass-Index; COPD: Chronic obstructive pulmonary disease; ERS: European Respiratory Society; FEV1: Forced expiratory volume in $1 \mathrm{~s}$; GOLD: Global Initiative for Chronic Obstructive Lung Disease; LTOT: Long-term oxygen therapy; pO2: Partial oxygen pressure; PR: Pulmonary rehabilitation; STST: Sit-to stand test; WBV: Whole-body vibration.

\section{Supplementary Information}

The online version contains supplementary material available at https://doi. org/10.1186/s12931-021-01688-x.

Additional file 1. Additional tables and figures.

\section{Acknowledgements}

Not applicable

\section{Authors' contributions}

RG, TS, IJ, and KK conducted the study design. TR, TS, DL, IJ, and RG performed the data collecting. $\mathrm{CN}$ and $\mathrm{RG}$ performed the data analyses. RG prepared the manuscript. RG, TS, DL, IJ, CN, ARK, and KK critically revised the manuscript. RG takes the responsibility for the integrity. All authors have read and approved the manuscript.

\section{Funding}

The authors declare that they have not received any funding for this study.

\section{Availability of data and materials}

The datasets generated and/or analyzed during the current study are not publicly available since this was not requested at the Ethical Committee. Datasets are available from the corresponding author on reasonable request.

\section{Declarations}

Ethics approval and consent to participate

This study was approved by the Ethics Committee of the Philipps-University of Marburg (approval number: 27/17)

Consent for publication

All patients provided written informed consent for the use of their pictures.

Competing interests

The authors declare that they have no competing interests.

\section{Author details}

${ }^{1}$ Department of Pulmonary Rehabilitation, Philipps-University of Marburg, German Center for Lung Research, Malterhoeh 1, 83471 Schoenau Am Koenigssee, Marburg, Germany. ${ }^{2}$ Institute for Pulmonary Rehabilitation Research, Schoen Klinik Berchtesgadener Land - Schoenau am Koenigssee, Königsee, Germany. ${ }^{3}$ Department of Prevention, Rehabilitation and Sports Medicine, Technical University of Munich, Munich, Germany. ${ }^{4}$ Department of Internal Medicine, Division of Pulmonary Diseases, Philipps University of Marburg, Marburg, Germany. ${ }^{5}$ Teaching Hospital, Paracelsus Medical University, Salzburg, Austria.

Received: 30 October 2020 Accepted: 18 March 2021

Published online: 04 May 2021

References

1. Armstrong WJ, Nestle HN, Grinnell DC, Cole LD, Van Gilder EL, Warren GS, et al. The acute effect of whole-body vibration on the hoffmann reflex. J Strength Cond Res. 2008;22:471-6. 
2. Abercromby AF, Amonette WE, Layne CS, McFarlin BK, Hinman MR, Paloski WH. Variation in neuromuscular responses during acute whole-body vibration exercise. Med Sci Sports Exerc. 2007;39(1642):1650.

3. Ritzmann R, Kramer A, Gruber M, Gollhofer A, Taube W. EMG activity during whole body vibration: motion artifacts or stretch reflexes? Eur J Appl Physiol. 2010;110(143):151

4. Wang W, Wang S, Lin W, Li X, Andersen LL, Wang Y. Efficacy of whole body vibration therapy on pain and functional ability in people with nonspecific low back pain: a systematic review. BMC Complement Med Ther. 2020;20:158.

5. Marin-Cascales E, Alcaraz PE, Ramos-Campo DJ, Martinez-Rodriguez A, Chung LH, Rubio-Arias JA. Whole-body vibration training and bone health in postmenopausal women: a systematic review and meta-analysis. Medicine. 2018;97:e11918.

6. Alashram AR, Padua E, Annino G. Effects of whole-body vibration on motor impairments in patients with neurological disorders: a systematic review. Am J Phys Med Rehabil. 2019;98(1084):1098.

7. Rogan S, de Bruin ED, Radlinger L, Joehr C, Wyss C, Stuck NJ, et al. Effects of whole-body vibration on proxies of muscle strength in old adults: a systematic review and meta-analysis on the role of physical capacity level. Eur Rev Aging Phys Act. 2015;12:12.

8. Zhou J, Pang L, Chen N, Wang Z, Wang C, Hai Y, et al. Whole-body vibration training - better care for COPD patients: a systematic review and meta-analysis. Int J Chron Obstruct Pulmon Dis. 2018;13:3243-54.

9. Gloeckl R, Jarosch I, Bengsch U, Claus M, Schneeberger T, Andrianopoulos $\checkmark$, et al. What's the secret behind the benefits of whole-body vibration training in patients with COPD? A randomized, controlled trial. Respir Med. 2017;126:17-24

10. Porto EF, Castro AA, Schmidt VG, Rabelo HM, Kumpel C, Nascimento OA et al. Postural control in chronic obstructive pulmonary disease: a systematic review. Int J Chron Obstruct Pulmon Dis. 2015;10:1233-9.

11. Loughran KJ, Atkinson G, Beauchamp MK, Dixon J, Martin D, Rahim S, et al. Balance impairment in individuals with COPD: a systematic review with meta-analysis. Thorax. 2020;75:539-46.

12. Beauchamp MK, Hill K, Goldstein RS, Janaudis-Ferreira T, Brooks D. Impairments in balance discriminate fallers from non-fallers in COPD. Respir Med. 2009;103(1885):1891

13. Hakamy A, Bolton CE, Gibson JE, McKeever TM. Risk of fall in patients with COPD. Thorax. 2018;73(1079):1080.

14. Yohannes AM, Raue PJ, Kanellopoulos D, McGovern A, Sirey JA, Kiosses DN, et al. Predictors of all-cause mortality in patients with severe COPD and major depression admitted to a rehabilitation hospital. Chest. 2016;149:467-73.

15. Spruit MA, Singh SJ, Garvey C, ZuWallack R, Nici L, Rochester C, et al. An official American Thoracic Society/European Respiratory Society statement: key concepts and advances in pulmonary rehabilitation. Am J Respir Crit Care Med. 2013;188:e13-64.

16. GOLD-Report Global Strategy of the diagnosis, management, and prevention of chronic obstructive pulmonary disease. 2020; www.goldcopd. org. Accessed 15 Sep 2020.

17. Troosters T, Gosselink R, Decramer M. Six minute walking distance in healthy elderly subjects. Eur Respir J. 1999;14(270):274.

18. Veilleux LN, Rauch F. Reproducibility of jumping mechanography in healthy children and adults. J Musculoskelet Neuronal Interact. 2010;10(256):266.

19. Siglinsky E, Krueger D, Ward RE, Caserotti P, Strotmeyer ES, Harris TB, et al. Effect of age and sex on jumping mechanography and other measures of muscle mass and function. J Musculoskelet Neuronal Interact. 2015;15:301-8.

20. Slinde F, Suber C, Suber L, Edwen CE, Svantesson U. Test-retest reliability of three different countermovement jumping tests. J Strength Cond Res. 2008;22(640):644

21. Holland AE, Spruit MA, Troosters T, Puhan MA, Pepin V, Saey D, et al. An official European Respiratory Society/American Thoracic Society technical standard: field walking tests in chronic respiratory disease. Eur Respir J. 2014:44:1428-46

22. Kon SS, Patel MS, Canavan JL, Clark AL, Jones SE, Nolan CM, et al. Reliability and validity of 4-metre gait speed in COPD. Eur Respir J. 2013;42:333-40.
23. Kon SS, Canavan UL, Jones SE, Nolan CM Clark AL, Dickson MJ, et al. Minimum clinically important difference for the COPD assessment test: a prospective analysis. Lancet Respir Med. 2014;2:195-203.

24. Jones SE, Kon SS, Canavan JL, Patel MS, Clark AL, Nolan CM, et al. The fiverepetition sit-to-stand test as a functional outcome measure in COPD. Thorax. 2013;68:1015-20.

25. Puhan MA, Siebeling L, Zoller M, Muggensturm P, ter Riet G. Simple functional performance tests and mortality in COPD. Eur Respir J. 2013;42(956):963.

26. Cooper BG, Stocks J, Hall GL, Culver B, Steenbruggen I, Carter KW, et al. The Global Lung Function Initiative (GLI) Network: bringing the world's respiratory reference values together. Breathe. 2017;13:e56-64.

27. Jirange P, Vaishali K, Sinha MK, Bairapareddy KC, Alaparthi GK. A crosssectional study on balance deficits and gait deviations in COPD patients. Can Respir J. 2021;2021:6675088.

28. Stolzenberg N, Belavy DL, Rawer R, Felsenberg D. Whole-body vibration versus proprioceptive training on postural control in post-menopausal osteopenic women. Gait Posture. 2013:38(416):420.

29. Oliveira CC, Annoni R, Lee AL, McGinley J, Irving LB, Denehy L. Falls prevalence and risk factors in people with chronic obstructive pulmonary disease: a systematic review. Respir Med. 2020;176:106284.

30. Chuatrakoon B, Ngai SPC, Sungkarat S, Uthaikhup S. Balance impairment and effectiveness of exercise intervention in chronic obstructive pulmonary disease-a systematic review. Arch Phys Med Rehabil. 2020. https:// doi.org/10.1016/j.apmr.2020.01.016.

31. Delbressine JM, Vaes AW, Goertz YM, Sillen MJ, Kawagoshi A, Meijer K, et al. Effects of exercise-based interventions on fall risk and balance in patients with chronic obstructive pulmonary disease: a systematic review. J Cardiopulm Rehabil Prev. 2020;40:152-63.

32. Beauchamp MK, Janaudis-Ferreira T, Parreira V, Romano JM, Woon L, Goldstein RS, et al. A randomized controlled trial of balance training during pulmonary rehabilitation for individuals with COPD. Chest. 2013;144:1803-10.

33. Sherrington C, Tiedemann A, Fairhall N, Close JC, Lord SR. Exercise to prevent falls in older adults: an updated meta-analysis and best practice recommendations. NSW Public Health Bull. 2011:22(78):83.

34. Camillo CA, Osadnik CR, van Remoortel H, Burtin C, Janssens W, Troosters T. Effect of "add-on" interventions on exercise training in individuals with COPD: a systematic review. ERJ Open Res. 2016. https://doi.org/10.1183/ 23120541.00078-2015.

35. Ko MC, Wu LS, Lee S, Wang CC, Lee PF, Tseng CY, et al. Whole-body vibration training improves balance control and sit-to-stand performance among middle-aged and older adults: a pilot randomized controlled trial. Eur Rev Aging Phys Act. 2017;14:11.

36. Lam FM, Chan PF, Liao LR, Woo J, Hui E, Lai CW, et al. Effects of wholebody vibration on balance and mobility in institutionalized older adults: a randomized controlled trial. Clin Rehabil. 2018:32:462-72.

37. Alvarez-Barbosa F, Del Pozo-Cruz J, Del Pozo-Cruz B, Garcia-Hermoso A, Alfonso-Rosa RM. Effects of whole-body vibration on functional mobility, balance, gait strength, and quality of life in institutionalized older people: a systematic review and meta-analysis of randomized controlled trials. J Aging Phys Act. 2020;28(219):230.

38. Alam MM, Khan AA, Faroog M. Effect of whole-body vibration on neuromuscular performance: a literature review. Work. 2018;59(571):583.

39. Bosco C, Colli R, Introini E, Cardinale M, Tsarpela O, Madella A, et al. Adaptive responses of human skeletal muscle to vibration exposure. Clin Physiol. 1999;19:183-7.

40. Cardinale M, Lim J. Electromyography activity of vastus lateralis muscle during whole-body vibrations of different frequencies. J Strength Cond Res. 2003;17(621):624.

41. Cardinale M, Rittweger J. Vibration exercise makes your muscles and bones stronger: fact or fiction? J Br Menopause Soc. 2006;12:12-8.

42. Burke JR, Schutten MC, Koceja DM. Kamen G Age-dependent effects of muscle vibration and the Jendrassik maneuver on the patellar tendon reflex response. Arch Phys Med Rehabil. 1996;77:600-4.

43. Marin PJ, Bunker D, Rhea MR, Ayllon FN. Neuromuscular activity during whole-body vibration of different amplitudes and footwear conditions: implications for prescription of vibratory stimulation. J Strength Cond Res. 2009:23:2311-6. 
44. Pepin V, Brodeur J, Lacasse Y, Milot J, Leblanc P, Whittom F, et al. Sixminute walking versus shuttle walking: responsiveness to bronchodilation in chronic obstructive pulmonary disease. Thorax. 2007;62:291-8.

45. Studenski S. Bradypedia: is gait speed ready for clinical use? J Nutr Health Aging. 2009;13:878-80.

46. Gloeckl R, Heinzelmann I, Seeberg S, Damisch T, Hitzl W, Kenn K. Effects of complementary whole-body vibration training in patients after lung transplantation: a randomized, controlled trial. J Heart Lung Transplant. 2015:34:1455-61.

47. Delecluse C, Roelants M, Diels R, Koninckx E, Verschueren S. Effects of whole body vibration training on muscle strength and sprint performance in sprint-trained athletes. Int J Sports Med. 2005;26:662-8.
48. Iwamoto J, Takeda T, Sato Y, Uzawa M. Effect of whole-body vibration exercise on lumbar bone mineral density, bone turnover, and chronic back pain in post-menopausal osteoporotic women treated with alendronate. Aging Clin Exp Res. 2005;17:157-63.

49. Beck BR, Norling TL. The effect of 8 mos of twice-weekly low- or higher intensity whole body vibration on risk factors for postmenopausal hip fracture. Am J Phys Med Rehabil. 2010;89:997-1009.

\section{Publisher's Note}

Springer Nature remains neutral with regard to jurisdictional claims in published maps and institutional affiliations.
Ready to submit your research? Choose BMC and benefit from:

- fast, convenient online submission

- thorough peer review by experienced researchers in your field

- rapid publication on acceptance

- support for research data, including large and complex data types

- gold Open Access which fosters wider collaboration and increased citations

- maximum visibility for your research: over $100 \mathrm{M}$ website views per year

At BMC, research is always in progress.

Learn more biomedcentral.com/submissions 